\title{
Stage I Uterine Corpus Cancer AJCC v6
}

National Cancer Institute

\section{Source}

National Cancer Institute. Stage I Uterine Corpus Cancer A/CC v6. NCI Thesaurus. Code C9207.

Stage I includes: I (T1, N0, M0); IA: (T1a, N0, M0); IB (T1b, N0, M0); IC (T 1C, N0, M0). T1:

Tumor confined to corpus uteri. T1a: Tumor limited to the endometrium. T1b: Tumor invades less than one-half of the myometrium. T1c: Tumor invades one-half or more of the myometrium. N0: No regional lymph node metastasis. M0: No distant metastasis.

(AJCC 6th ed.) - 2003 